\title{
Arsenic retention and distribution in a treatment wetland prototype
}

\author{
M.T. Alarcón Herrera ${ }^{1}$, M.A. Olmos-Márquez ${ }^{2}$, J. Ochoa ${ }^{3}$ \& I.R. Martin-Domínguez ${ }^{1}$ \\ ${ }^{1}$ Centro de Investigación en Materiales Avanzados SC (CIMAV), Chihuahua, Chih., Mexico \\ ${ }^{2}$ Universidad Autónoma de Chihuahua (UACH), Chihuahua, Chih., Mexico \\ ${ }^{3}$ Instituto Nacional de Investigaciones Forestales, Agrícolas y Pecuarias, Campo Experimental La Laguna, \\ Matamoros, Coah., Mexico
}

\begin{abstract}
The aim of this study was to investigate the plant's arsenic mass retention and the distribution of As along the wetland flow gradient and the soil in the wetland mesocosmos. Experiments were carried out in laboratory-scale wetland prototypes, two planted with E. macrostachya and one without plants. Samples of water were taken at the inlet and outlet of the wetlands during the 33-week test period. At the end of the experiment, plants and soil (silty-sand) from each prototype were divided in three equal segments (entrance, middle and exit) and analyzed for their arsenic content. Results revealed that the planted wetlands have a higher As-mass retention capacity (87-90\% of the total As inflow) than prototypes without plants (27\%). Results As mass balance in the planted wetlands revealed that $78 \%$ of the total inflowing As was retained in the soil bed. Nearly $2 \%$ was absorbed in the plant roots, $11 \%$ was flushed as outflow, and the fate of the remaining $9 \%$ is unknown. In the prototype without plants, the soil retained $16 \%$ of As mass, $72 \%$ of the arsenic was accounted for in the outflow, and $12 \%$ was considered unknown.
\end{abstract}

\section{INTRODUCTION}

Constructed wetlands (CWs) are an innovative technology in arsenic water treatment, which has proven to be both effective and affordable. They utilize the interaction of plants and microorganisms in the removal of different pollutants, among them metals and metalloids (Vymazal, 2005). To understand As-retention capacities, it is necessary to analyze the specific behavior of arsenic during uptake by plants, as well as the influence of media (soil) retention (Frohne et al., 2011). The mass balance of As in treatment wetlands, both in the presence and absence of wetland plants, could yield insights on the capacity of CWs to retain arsenic from water. Therefore, the objectives of this study were to investigate the distribution of total arsenic in main wetland compartments (plants and soil bed) and in three segments (entrance, middle and exit) of each unit along the flow path.

\section{METHODS/EXPERIMENTAL}

\subsection{Experimental design: laboratory-scale prototypes}

The three wetland prototypes used in this study were built with acrylic (length: $150 \mathrm{~cm}$, width: $50 \mathrm{~cm}$, height: $50 \mathrm{~cm}$ ). The prototypes were uniformly filled with $200 \mathrm{~kg}$ of silt sand (density of $0.90 \mathrm{~g} \mathrm{~cm}^{-3}$, porosity of $31 \%$, and hydraulic conductivity of $\left.6.89 \times 10^{-4} \mathrm{~cm} \mathrm{~s}^{-1}\right)$. The support for the plants was a bed $30 \mathrm{~cm}$ in depth, composed of silty sand with a particle size between 0.007 and $0.47 \mathrm{~cm}$. Rough gravel $(2.5-4.0 \mathrm{~cm})$ was used to create uniform water distribution at the entrance and exit of each unit. The water level was adjusted to $5 \mathrm{~cm}$ below the surface of the sand bed. Two prototype wetlands (W1 and W2) were planted with E. macrostachya, and one prototype remained unplanted (W3) as a control.

\subsection{Arsenic mass balance determination}

After 33 weeks of operation, the experiment was ended. An arsenic mass balance was performed in each prototype unit and within the three segments by considering the total As-mass input, the total As-mass output, and the total As retained in the soil and plant biomass. The remaining (loss or gain) of arsenic from the mass balance was considered to be unknown. The total As-mass input and output in each unit was calculated from the cumulative total As-mass inflow and outflow during the whole operation period of 33 weeks.

\section{RESULTS AND DISCUSSION}

\subsection{Arsenic removal efficiencies of constructed wetland systems}

Figure 1 shows the total amount of arsenic mass inflow and the total arsenic retention in all three corresponding units during the whole study period of 33 weeks. A total inflow As-mass of $1,441 \mathrm{mg}$ was fed to each prototype, and a total of 182,140 , and $1,034 \mathrm{mg}$ As mass was flushed through the outlet of units W1, W2 and $\mathrm{W} 3$, respectively. Therefore, a cumulative total mass of 1,259, 1,301 and $407 \mathrm{mg}$ As mass was retained in each unit. This means a retention of nearly $87 \%$, $90 \%$ and $28 \%$ in units $\mathrm{W} 1, \mathrm{~W} 2$ and $\mathrm{W} 3$, respectively (Fig. 1). 


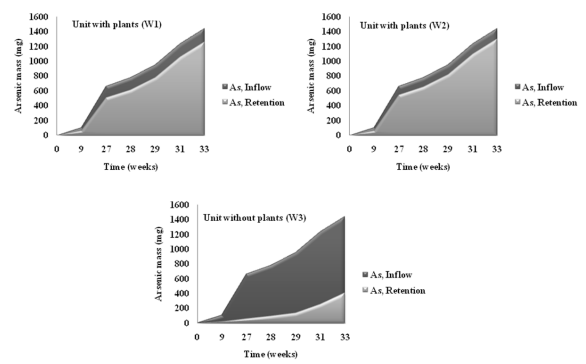

Figure 1. Cumulative As-mass inflow and retention in the three prototype units.

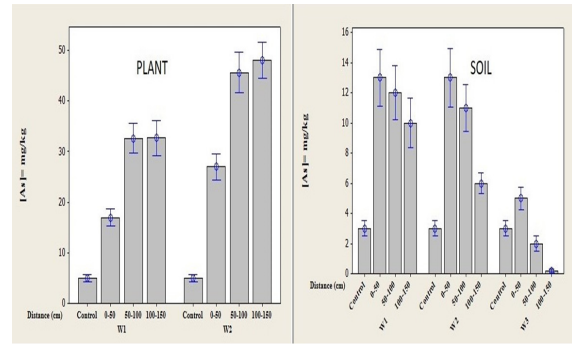

Figure 2. Concentration of total arsenic in plant roots and soil measured in each segment of the prototype (W1, W2 and W3).

\subsection{Arsenic retention by E. macrostachya}

We quantified the arsenic retained by plants in each of the three segments in each prototype. The prototypes with E. macrostachya showed greatest arsenic retention in the exit section, reaching average root arsenic concentrations of $33 \pm 1.37$ and $47 \pm 1.42 \mathrm{mg} \mathrm{kg}^{-1}$. The entrance sections retained $17 \pm 0.70$ and $27 \pm 1.01 \mathrm{mg} \mathrm{kg}^{-1}$ in $\mathrm{W} 1$ and $\mathrm{W} 2$, respectively (Fig. 2). The mean total arsenic concentration in the roots of the planted units (W1 and W2) was $27 \pm 1.9$ and $40 \pm 2.8 \mathrm{mg} \mathrm{kg}^{-1}$ (dry weight), respectively. This concentration was also remarkably low in the shoots of the respective prototypes $(0.30 \pm 0.02$ and $0.73 \pm 0.05 \mathrm{mg} \mathrm{kg}^{-1}$ ).

\subsection{Arsenic retention in soil}

At the end of the experiment, soil was also collected from six different segments of each prototype. Results are presented in Figure 2, which shows how As concentrations decreased between the entrance and exit segments from $13.05 \pm 0.75$ to $5.86 \pm 0.26 \mathrm{mg} \mathrm{kg}^{-1}$ (dry weight). In the unplanted prototype, $\mathrm{W} 3$, the arsenic concentration values presented the same trend but also significantly lower concentrations in all three segments $(4.91 \pm 0.30$, $1.86 \pm 0.20$ and $0.14 \pm 0.05 \mathrm{mg} \mathrm{kg}^{-1}$ (dw) for the entrance, middle and exit segments, respectively) (Fig. $3)$. Arsenic retention in the soil of the prototypes showed an inverse behavior to that of the plants. A better retention of Arsenic was obtained at the entrance section of each unit.

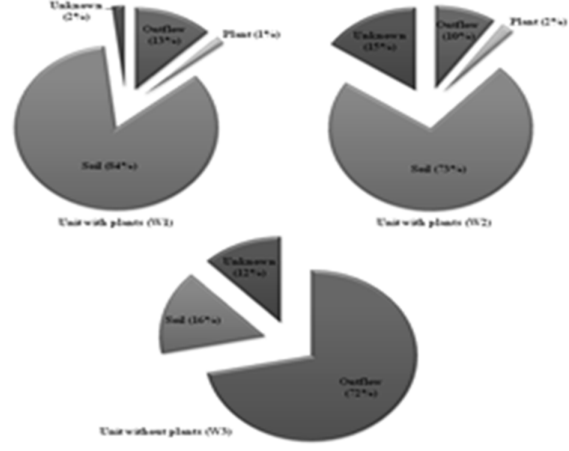

Figure 3. Mass balance of arsenic as percentage of inflowing total arsenic mass in the prototypes of subsurface flow constructed wetlands W1, W2 and W3.

\subsection{Arsenic mass balance and distribution}

Figure 3 shows the mass balance obtained for the different components of the system (plants, soil, outlet water, and unknown), calculated as a percentage of the As mass in the feed water in each unit.

The total mass balance showed that the soil with the plants is the main source of As retention system in units $\mathrm{W} 1$ and $\mathrm{W} 2$. The mass of arsenic that was retained in the units with plants was 1,210 and $1,044 \mathrm{mg}$ for W1 and W2, respectively, while the unit without plants (W3) retained only $230 \mathrm{mg}$. The units with plants (W1, W2) presented a smaller quantity of arsenic in the exit water (182 and $140 \mathrm{mg}$, respectively) than the unit without plants W3 $(1,034 \mathrm{mg})$. The plants' retention of arsenic was very small ( $2 \%)$ in comparison to that obtained from the soil-bed of units W1 and W2, which retained $84 \%$ and $72 \%$, respectively.

\section{CONCLUSIONS}

The mass balance allows us to better analyze the arsenic distribution in the different parts of the system, as well as the retention of arsenic in the different segments of the $\mathrm{CW}$ prototypes. The plants play an important role in the As retention through different chemical, physical and microbiological process which do not occur in the $\mathrm{CW}$ without plants.

\section{ACKNOWLEDGEMENTS}

This work was financially supported by National Council for Science and Technology (CONACYT), within the Program Attention to National Problems.

\section{REFERENCES}

Frohne, T., Rinklebe, J., Diaz-Bone, R. \& Du Laing, G. 2011. Controlled variation of redox conditions in a floodplain soil: impact on metal mobilization and biomethylation of arsenic and antimony. Geoderma. 160(3-4): 414-424.

Vymazal, J. 2005. Removal of heavy metals in a horizontal sub-surface flow constructed wetland. J. Environ. Sci. Health Part A 40(6-7): 1369-1379. 